\title{
USE OF INFORMATION AND COMMUNICATION TECHNOLOGY TOOLS IN DISTRIBUTED PRODUCT DESIGN STUDENT TEAMS
}

\author{
Horvat, Nikola (1); \\ Becattini, Niccolò (2); \\ Škec, Stanko (1) \\ 1: University of Zagreb; \\ 2: Politecnico di Milano
}

\begin{abstract}
This paper analyses the use of information and communication technologies (ICTs) in a distributed product design project-based learning (PBL). The paper presents the ICT use of five international student teams during three product design phases: identification of opportunities, conceptual design, embodiment design. General results show that student teams used around 30 different ICTs for both taskwork and teamwork. Students reported that they used previously known ICTs or ICTs properly introduced to them during the initial course workshop. Results also show that team members often work individually on their tasks and use various procedures to share their results. Also, teams conduct some activities synchronously, suggesting the need for teams to have a collaborative workspace. Cloud-based collaborative ICTs (e.g. whiteboard, computer-aided design, document editor, task management) showed huge potential for individual and team tasks. Hence, educators and teams should carefully consider which ICTs to implement and learn, as it might greatly impact the execution of the product design PBL course.
\end{abstract}

Keywords: Design education, Project-based learning, Collaborative design, Distributed teams, Technology

Contact:

Horvat, Nikola

University of Zagreb, FSB

Department of Design

Croatia

nikola.horvat@fsb.hr 


\section{INTRODUCTION}

Project-based learning (PBL) is a common teaching pedagogy in product design (Dym et al., 2005). It encourages students to participate actively, integrate knowledge and keep up the motivation by working on real-world problems, hence supporting contextual learning (Dym et al., 2005; Verstegen et al., 2016). Furthermore, when the PBL course is designed for teams, students acquire collaboration skills as they work on interdependent tasks and often discuss problems, solutions and processes with their team members. Hence, team-based PBL courses also facilitate knowledge acquisition through collaborative learning (Verstegen et al., 2016).

In these courses, students use a wide variety of information and communications technology (ICT) tools (Verstegen et al., 2016) to help them achieve objectives. By learning new tools used in a realworld setting, students can acquire an additional set of skills to improve their performance in the PBL courses and a real-world setting. Indeed, the progressive adoption and the diffusion of ICT tools in professional settings witness their positive impact in many sectors where communication is crucial, including product development (Kawakami et al., 2015).

The use of ICT tools in educational settings is largely influenced by previous experience with the tool (Brisco et al., 2016). However, students might not always have the experience and knowledge for the ICT tools planned for fulfilling course objectives. Hence, they have to choose whether to address course objectives using familiar tools or by learning and utilizing new tools. If the introduction of new ICT tools is based on a self-learning approach, students might spend a significant amount of time learning them (Brisco et al., 2020). Moreover, students might quickly lose interest in adopting new ICTs since they can face a steep learning curve when working with them (Verstegen et al., 2016). Very few studies relate to students' limited knowledge of ICT tools and their restricted time to learn and implement optimal tool. Consequently, students' outcome from the PBL course might be affected. Furthermore, although there are some suggestions about which ICT tools students need and use during product design PBL courses (Brisco et al., 2016, 2019; Verstegen et al., 2016), previous research reported the lack of tool support for product design PBL courses (Becattini et al., 2020; Vukašinović and Pavković, 2017). Therefore, it is still unclear which tools students use for different tasks during product design.

Given the importance of PBL in design education and the need to support PBL courses with available ICT tools, it is necessary to understand which tools are being used in a distributed product design PBL course. Therefore, this paper gives insights into the following research question: "How ICT tools support distributed student teams in a product design PBL course?"

To answer the question, this paper gives an overview of previous work in Section 2, describes the context and methods used to gather data in Section 3, presents results in Section 4, and discusses findings and implications in Section 5. Finally, Section 6 concludes our findings and gives an outlook for future work.

\section{PRODUCT DESIGN PBL}

Educators in product design often utilise PBL pedagogy within associated project courses (Dym et al., 2005). These courses are based on problem-based learning, which can be described as a five-step process (Hmelo-Silver, 2004): 1) Understanding the problem, 2) Exploration of the problem, 3) Identification, retrieval and interpretation of relevant information, 4) Exploration of possible solutions and formulation of the solution to the problem, and 5) Analysis of the solution and of the process that led to its generation.

In design education, these courses are designed in various ways, focusing on certain aspects of problemsolving. Some focus more on the identification of a relevant problem to be solved (Leung et al., 2019), while others use problems proposed by students (Stone et al., 2018) or industry (Becattini et al., 2020; Vukašinović and Pavković, 2017). These courses might also have different goals, as some might focus on the development of a minimum viable product (Leung et al., 2019) or functional prototype (Stone et al., 2018; Vukašinović and Pavković, 2017), while others focus more on the development of solutions to a predefined level of details (Becattini et al., 2020; Xiao et al., 2018). Other differences among the product design PBL courses are in the course's execution, as some courses are designed as co-located (Xiao et al., 2018) while others are distributed (Becattini et al., 2020; Leung et al., 2019). In a distributed environment, many challenges impede successful collaboration, such as overpowering members, lack of motivation, managing personalities, access to software, overcoming language barriers (Brisco et al., 2019). However, product design PBL courses might overcome these challenges by emphasising the 
importance of regular communication and prompt responses. Additional suggestions are to keep communication methods simple, agree on team protocols and design methods, utilise knowledge management techniques and synchronous work (Brisco et al., 2019). Students usually deliver their work at several project milestones, usually after each project phase. These deliverables are generally in the form of reports and presentations (Becattini et al., 2020; Stone et al., 2018) and could include other materials such as 3D models, posters or videos (Becattini et al., 2020).

Hence, PBL courses are an information-intensive process, and therefore communication plays a relevant role, especially in a team context. Teams need to share information on the problem to gain a shared understanding of the same, perform an efficient exploration etc. Therefore, to help students manage this information-intensive process, some product design PBL courses have an initial workshop (Leung et al., 2019). These workshops provide relevant information about the problem to be solved, design process or ICT tools that might help students throughout the course. Other educators deliver this information through several lectures as part of the course (Becattini et al., 2020; Vukašinović and Pavković, 2017).

\subsection{Use of ICT tools in product design PBL courses}

In PBL courses, students use various ICT tools, which can be categorised into multimedia, simulations, serious games, communication and information sharing tools, task-specific tools and other tools such as scheduling or notepads (Verstegen et al., 2016).

Brisco et al. (2016) analysed students' usage of mobile devices and online social networks in a distributed design course. They found that students show a preference for using familiar ICT tools and change the tool when they encounter problems such as lack of support or unavailability of mobile devices (Brisco et al., 2016). Furthermore, they also identified that students do not extract requirements for the ICT tools and rarely discuss which tool to use (Brisco et al., 2016). Beside communication tools, many authors suggested the use of a digital whiteboard. Verstegen et al. (2016) suggested that introducing interactive whiteboards should be beneficial for various individual and collaborative tasks. These whiteboards enable structuring prior knowledge, integrating newly acquired knowledge and sharing the knowledge across team members (Verstegen et al., 2016). Vukašinović and Pavković (2017) reported that the graphical content on a collaborative whiteboard facilitated communication in terms of solution explanation. They also reported that students use whiteboards extensively on the meetings conducted via video conferencing tools (Vukašinović and Pavković, 2017).

Based on the abovementioned wide variety of ICT tools being used within PBL courses, Becattini et al. (2020) proposed an e-learning infrastructure consisting of a learning management system, file repository, distant communication tools, instant messaging, project management, concept mapping and 3D computer-aided design (CAD) tool. For the course management, Becattini et al. (2020) used email, instant messaging, file repository and learning management system, similar to the ICT tools proposed by Leung et al. (2019).

Even though researchers reported that students use various ICT tools in a distributed product based PBL courses, many challenges to their effective use still exist. Students can overcome some challenges using video conferencing, instant messaging and collaborative document editing tools (Brisco et al., 2019). However, learning new ICT tools might require a significant amount of time. Hence, this acquisition of new ICT tool skills, coupled with the information-intensive PBL course, might overload students with new information (Verstegen et al., 2016). Although previous research reported some tools that students use, none of them provides comprehensive information on using ICT tools in distributed student teams throughout the whole product design PBL course. Thus, this study aims to analyse which ICT tools constitute a PBL course and how they are used for various product design tasks.

\section{PRODUCT DESIGN PBL COURSE AND RESEARCH METHOD}

The study follows a case study research design of student teams working in a product design PBL course. The course is organised as a collaboration of four universities in which five eight-member mechanical engineering student teams worked on product design problems proposed by Electrolux and Elettrotecnica Rold. Three female and 37 male students on both undergraduate and graduate level participated in the course. Each team consisted of two members from each institution (University of Zagreb, Politecnico di Milano, University of Ljubljana and TU Wien). During the course, each team had one or two academic coaches who worked as the team's facilitators. 
The course started with an initial four-day workshop to help students form teams, transfer knowledge about design methods and ICT tools, and introduce a problem to be solved. More specifically, the course staff organised a workshop around a few topics: user and market research, problem framing, patent landscaping, idea generation, project management and communication. Also, the course staff provided students with ICT tools and internet sources that might help them throughout the course (see Table 1). To actively engage students in learning the ICT tools, the staff suggested that students open these tools and conduct a few tasks. On the second day of the workshop, besides lectures provided by the course staff, the company representatives introduced two sustainability-related problems. One problem was excessive water use in washing machines while the other was high energy consumption of dishwasher during the drying cycle. Students' task was to provide innovative solutions for the two posed problems. In addition to transferring knowledge in the initial workshop, the course staff delivered two general lectures related to computer-aided design and engineering and product data management at halfway of the course. The course staff recommended one CAD tool for each student team, expecting them to take the self-learning approach to use these tools.

After the initial workshop, the course followed three product design phases (identification of opportunities, conceptual design, embodiment design). Each phase finished with a project review involving company representatives, for which students prepared a presentation and a 10-page report. During the first phase, students conducted various searches for both problems. They also proposed a few visions on how they would like to proceed. In the second phase, students had to develop several concepts based on the vision that the companies have chosen after the first project review (related to either washing machine or dishwasher problem). After the conceptual design phase, teams worked on the embodiment design of the concept chosen by the company. Besides the 10-page report and presentation, in the third project review, teams had to deliver a virtual prototype, technical documentation and bill of materials for their solution. About two weeks after the third review, the teams presented their final design during a workshop with the company management and technical staff. For this final workshop, all the teams incorporated rendered images and a video of their solution into the presentation.

Table 1. ICT tools introduced to teams

\begin{tabular}{|c|l|}
\hline ICT tool & \multicolumn{1}{c|}{ Possible use } \\
\hline Adobe Connect* & Meetings, virtual brainstorming \\
\hline Moodle* & Communication with a coach, Information about the process and ICTs \\
\hline OwnCloud** & Storing files \\
\hline MS Excel*** & Gantt chart \\
\hline Trello** & Task management \\
\hline Miro** & Problem framing, Functional decomposition, Idea generation \\
\hline Espacenet* & Patent landscaping \\
\hline MS Word*** & Agenda, meeting minutes \\
\hline CAD/CAE/PDM* & CAD modelling, analysis, data management \\
\hline$*$ - presented functionalities; $* *$ - active learning; $* * *$ - presented in context
\end{tabular}

\subsection{Data collection and analysis procedure}

The authors (also part of the course staff) conducted several semi-structured interviews with the team members to collect data about the ICT tools and their usage. They interviewed the five teams twice (after phase 1 and at the end of the project). This shed light on potentially lacking contents within the course and helped explore how the students used ICT tools during the project. In addition to interviews, coaches and team members created diaries regarding the use of tools. Thanks to both interviews and evidence collected in diaries concerning projects' activities (e.g. frequency of use, frequency of team communication), the use of ICT tools across the course emerged.

All the interviews and diaries were analysed through several steps following the thematic coding approach (Robson and McCartan, 2016). First, the authors checked the interviews and diaries to note when an ICT tool was mentioned, together with the team process for which the team used it. The authors iteratively developed a list of tasks considering various sources, such as previous literature, course syllabus, and collected data. These tasks describe what the team is doing (taskwork) and how the team interacts (teamwork) - a common categorisation of working within teams (Cash et al., 2019). Tasks from the literature were mainly related to teamwork (Communication, Data management, Task 
management, Delivering information about the design process), with only few of them related to taskwork (CAD modelling, Writing a report, Creating presentation) (Becattini et al., 2020; Brisco et al., 2019; Leung et al., 2019). Tasks from the course syllabus were derived from the initial workshop and lectures. They were also categorised into teamwork (Communication, Data management, Task management, Design process information) and taskwork (Technology and idea search, Market search, Problem Framing, Functional decomposition, Idea generation, CAD modelling, Calculations). Finally, based on the interview and diaries, the authors added tasks that supported project deliverables (Technical drawings, Bill of Materials, Sketching, Rendering, Creating video, Writing a report, Creating presentation). As PBL courses are an information-intensive process, an internal reporting of the retrieved information (Internal report) is added. All other ICT tools were categorised as residuals (Other).

To validate the tasks and extracted data from interviews and diaries, the authors sent initial tables to all the coaches and team members (each team got a different table tailored to the obtained data). All the coaches and most of the students ( 23 out of 40 ) checked the table and reported ICT tools that they used.

\section{RESULTS}

This section presents student teams' usage of ICT tools for teamwork (Subsection 4.1) and taskwork (Subsection 4.2) throughout the product design PBL course. The five teams, in total, used 64 different tools in 20 different tasks. Figure 1 visualises the use of tools across tasks and teams. The task type is positioned on the vertical axis and the ICT tool on the horizontal axis, while the teams are colourcoded. This type of visualisation enables the clear identification of tools used across teams, tools that are used for more than one task, and tasks that require the usage of more than one tool.

\subsection{Use of ICT tools while doing teamwork}

Most of the ICT tools students used for communication (13 of them - see Figure 1), with video conferencing (e.g. Adobe Connect, MS Teams), instant messaging (e.g. WhatsApp) and email being common across all teams. Teams used video conferencing tools to conduct formal meetings with the coach and among themselves. Also, some teams reported that a team leader used video conferencing to communicate with each team member one-on-one. During both formal and informal meetings, teams often used the feature to share the screen to present their work since the last meeting. Furthermore, teams used video conferencing for communication while working collaboratively on some tasks (e.g. problem framing, idea generation, CAD modelling). They used more than one video conferencing tool due to experienced technical issues (e.g. lack of local licenses) or limitations while working in subteams (e.g. tool restriction to just one virtual room at a time). For general communication, teams used instant messaging tool (WhatsApp), and they usually reported having several instant messaging groups (depending on the work distribution) and chatting privately. Also, they used it for quick exchange of the findings and sometimes to distribute tasks. Some of the teams also used it to communicate with their coach. An email has been used by team members for formal communication, usually including coaches, to distribute meeting agenda and minutes.

Teams used several cloud tools for data management (e.g. Owncloud, Google Drive). After creating taskwork-related files in a non-collaborative manner, team members stored their files on one of the cloud platforms to share them with others and allow their later reuse. For some teams, this file-sharing solution enabled them to integrate their individual and subteam work into a final version. However, some students did not use cloud repository tools to exchange documents but rather done it in a more agile manner, using either sharing the documents via instant messenger (e.g. WhatsApp) or via task management tool (e.g. Trello). For specific document types (e.g. CAD), some teams used platformspecific data management tools that faster exchange and iteration on those documents (e.g. Autodesk Fusion 360, Onshape). Hence, teams usually used more than one ICT tool for data management. For task management purposes, teams usually used board management tools (e.g. Trello) for managing day-to-day tasks. Teams used these boards to track tasks that are to be done, tasks that the team is currently doing and tasks that the team already completed, together with deadlines and a responsible team member. In most of the teams, a team leader was usually responsible for managing and keeping the board up to date, while other members used the board to keep track of other interdependent tasks and comment on others' work. After the first phase, one team stopped using the board management tool. They perceived that meeting minutes, coupled with constant communication via an instant messaging tool, were sufficient for their task management purposes. To identify tasks to be conducted 
and assign deadlines, teams sometimes used a spreadsheet (e.g. MS Excel, Google Spreadsheet) and created a Gantt chart. Furthermore, this high-level management of team activities was usually supported by the coaches and the course through various design process supplementary materials. These materials were available to students via Moodle. Furthermore, some coaches provided additional materials to help students plan their phase, using either communication tools (e.g. email, instant messaging) or management tools (e.g. Trello) to send the materials.

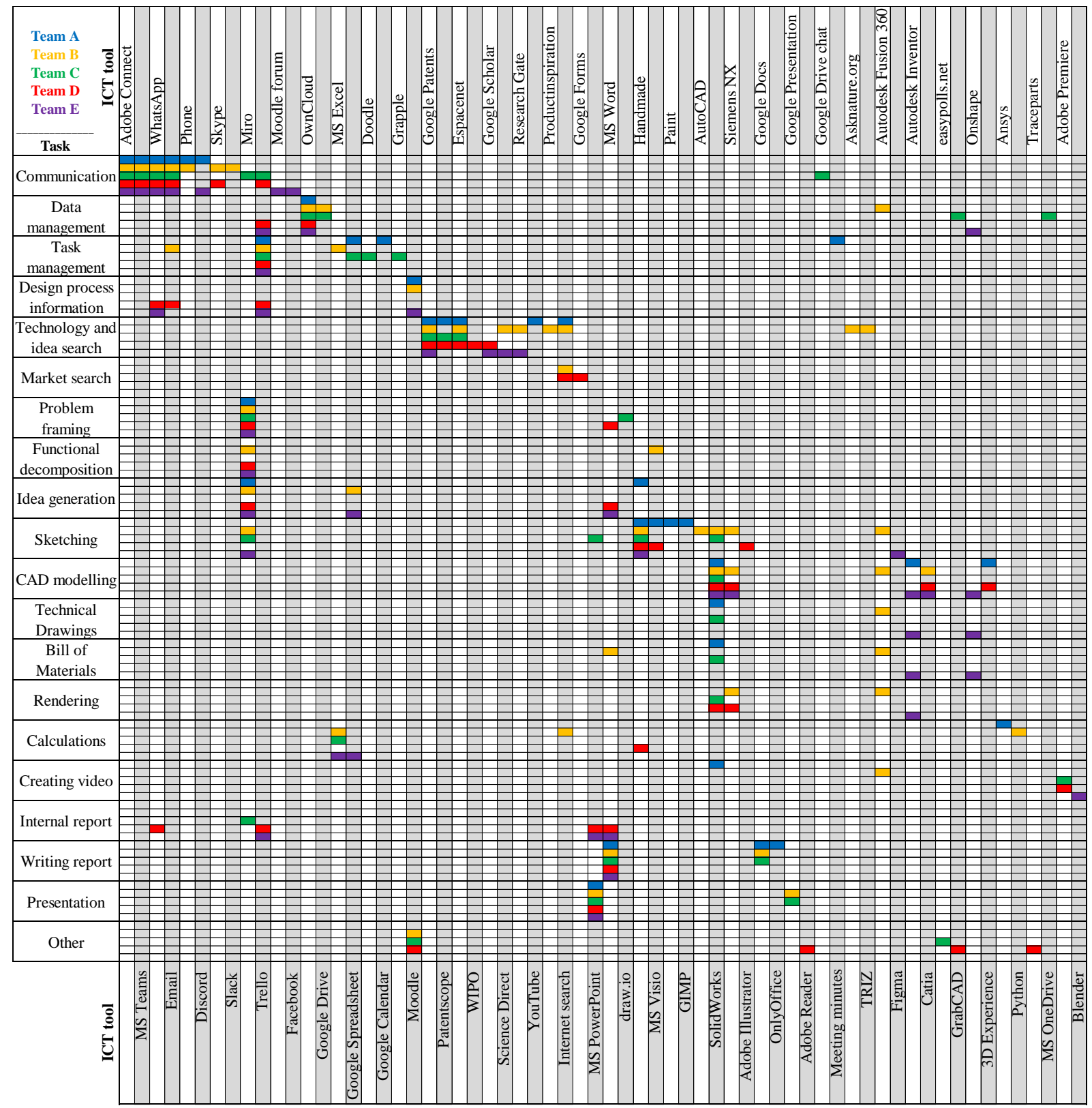

Figure 1. Use of ICTs in a PBL course

\subsection{Use of ICT tools while doing taskwork}

Team members also used various ICT tools to help them do their taskwork (Figure 1). For the technology and idea search, all the teams used at least one patent database (e.g. Google Patents, Espacenet). Additionally, some teams also searched for research papers using various databases (e.g. Google Scholar, ScienceDirect) or even social platforms (e.g. ResearchGate). One team reported the use of YouTube and said that video content helped them understand various technologies during the initial phase. Some teams used internet sources with databases related to physical effects (e.g. productioninspiration.com), nature-inspired solutions (e.g. asknature.org) and patent-inspired principles (e.g. Oxford Creativity - triz.co.uk). Only two teams reported using ICT tools for market research, and both of them reported the use of general Internet search. Only one team created a survey 
(using Google Forms) to gather more information about the potential market. As all these tools for searching (technology, idea or market) enable only individual use, teams usually separated work among themselves about who will search for what and then shared information on a meeting or through instant messaging. Furthermore, teams reported that besides the outcomes of these searches, they sometimes shared the search process so that others can become familiar with different approaches and integrate them into their search. None of these tools enabled saving information, which team members could use to present their searches to the team or store information for later use. Therefore, the teams created a lot of internal reports using either document tools (e.g. MS Word, MS PowerPoint), collaborative whiteboard (e.g. Miro) or comments in a task management tool (e.g. Trello).

This newly acquired information from various searches helped the teams in problem framing. For this task, teams extensively used a collaborative whiteboard to create a network of problems (Becattini et al., 2015) - a method introduced to them in an initial workshop. In this process, some teams created several networks of problems, each relating to the topic searched by an individual or a subteam (usually two to four members). In contrast, other teams created one network of problems that included inputs from all the searches. This integration of individual searches to a team/subteam-level network of problems was conducted either synchronously or asynchronously, depending on the members' availability. The synchronous building of a network of problems mostly involved only a subteam. In some cases, this subteam consisted of members that previously worked together on technology and idea search task (i.e. creating a network of problems for a common topic on a subteam level). In other cases, the subteam was created specifically to build a network of problems based on team knowledge and reported searches (i.e. building a network of problems for the whole team). During this synchronous building of a network of problems, a subteam communicated via video conference and had available cursor focus of each subteam member while working on a collaborative whiteboard. The asynchronous building of a network of problems involved members working individually, either building a team/subteam-level network of problems or building their network of problems. In the latter case, members did not always use a collaboration whiteboard but sometimes switched to other tools (e.g. draw.io) and then shared their work through data management ICT tools. A similar pattern has also been observed while doing functional decomposition (Pahl et al., 2007) and generating ideas using a morphological table (Pahl et al., 2007). Indeed, in these tasks, teams often used a collaborative whiteboard (e.g. Miro) and some other ICTs that are not aimed at enabling collaborative work (e.g. MS Visio, MS Word). In earlier phases, teams frequently represented ideas with the sketch. They created these sketches in various ways, ranging from hand-made and free-form made on a collaborative whiteboard (e.g. Miro) to sketches created using CAD tools (e.g. SolidWorks, AutoCAD, Autodesk Fusion 360). In general, a team member created a sketch individually using an ICT tool in which they were already experienced. These sketches were then presented using communication tools, or they were transferred to a collaborative ICT tool (e.g. Google Spreadsheet, Miro) so that all the members have access to the sketch.

For CAD modelling, most of the teams used more than one tool. SolidWorks was extensively used by all the teams, even though only one team was assigned to use this tool. Teams used these traditional CAD tools (e.g. SolidWorks, Catia) to create CAD models individually and then incorporated them into a sub-/assembly. To assemble parts created in different CAD tools into the assembly, teams used standard file formats for CAD exchange (e.g. STEP), which they shared through data management tools (e.g. OwnCloud, Google Drive). This approach resulted in a final assembly model without a feature tree of constituent parts, so teams had longer iteration cycles when modifying CAD models. Students reported that team members had a different background, so they were familiar with different CAD tools. As the timing to learn another CAD tool was short, some team members have chosen to work in the familiar CAD tool. In the two teams that were introduced cloud-based CAD tools (e.g. Autodesk Fusion 360, Onshape), only two or three members learned that tool. In addition to using it as a traditional CAD tool, they also used it to work synchronously. During these collaboration periods, members reported that they also used a video conference tool and worked like that for hours. The members that acquired the skills to use these cloud-based CAD tools reported that they are very helpful for collaboration as they make it easy to share files and always have an up-to-date version of the model. To create technical drawings, bill of materials and rendering, teams used one or two CAD modelling tools. These tasks included limited collaboration, as team members usually worked individually on them and shared their outcomes through data management tools (e.g. OwnCloud, Trello, Autodesk Fusion 360). The use of ICT tools for calculations and creating video showed a 
similar pattern. For calculations, only one team reported using computer-aided engineering (e.g. Ansys), while other teams mostly used a spreadsheet (e.g. MS Excel). For creating videos, usually only one individual worked in a CAD tool or a dedicated ICT tool for making videos (e.g. Adobe Premiere).

After each of the phases, teams had to deliver a report and a presentation. For these tasks, the teams used either Microsoft or Google solutions (Word or Docs for writing report, and PowerPoint or Presentation for creating presentation). Some teams created a report synchronously, using cloudplatforms (e.g. Google Docs), which reduced the document assembler's work. On the other hand, other teams divided into subteams that had to deliver their part of the report within the page-limit constraints while working independently. The one team member then assembled the whole document, making it readable and consistent. Creating a presentation usually had a slightly different approach. One or two members were creating slides, while others reviewed them or created supporting materials (such as renders, videos, sketches etc.). Finally, teams used other ICT tools individually to either give feedback to the course (Moodle questionnaires), to find standard CAD models (e.g. GrabCAD, Traceparts) or to vote while making decisions related to various design aspects (e.g. easypolls.net).

\section{DISCUSSION AND IMPLICATIONS}

The five teams used various ICT tools during the course, with some tools being used for more than one task while others were used for only one task. This section discusses these results around two main findings: the importance of prior experience in using ICT tools and the benefits of cloud-based tools.

\subsection{Previous experience and adopting suggested ICT tools}

During the course, teams used various ICT tools to help them in product design. Some of those tools were already familiar to students (e.g. CAD tool that they learned at their university, MS Office tools, WhatsApp, file repository tool), while others not (e.g. Adobe Connect, Trello, Miro, Onshape, Autodesk Fusion 360, Moodle). Even though the course staff introduced the basic set of ICT tools during the initial workshop, students used more than one communication tool. Some of them opted for tools they were already familiar with (e.g. Skype, Discord). Others switched from the suggested tool to alternative ones that were perceived as less sensitive to technical problems or which provide additional functionalities (e.g. parallel communication). Students showed a similar effect of previous experience while using sketching tools. Some students created their sketches using ICT tools that are not primarily designed for this purpose (e.g. AutoCAD). This pattern is emphasised during the CAD modelling phase, as teams used different $\mathrm{CAD}$ tools and exchanged files through a standard file exchange format. Having various tools for the CAD purpose has a consequence of longer iteration cycles, as teams reported that they could not edit the parts due to lack of feature tree. Even though current CAD tools have available direct editing feature, which could cross this barrier, none of the students reported its use.

Students reported that they were more familiar with the tools they have chosen themselves and did not have time to learn another ICT tool given the course's high pace. Therefore, previous experience is one of the main forces that drive a decision on choosing another ICT tool (Brisco et al., 2019). Hence, students might feel that learning additional CAD tools is time-consuming and presents a distraction - a common reason for not adopting a suggested ICT tool (Verstegen et al., 2016). Another reason for not adopting suggested tools might be a lack of perceived benefit. For example, one of the teams switched from using a proposed task management tool (Trello) to use only meeting minutes for distributing tasks. This team reported that they did not see the purpose of using a task management tool. Furthermore, some team members assigned to use cloud-based CAD tools also said that they did not see the purpose of learning another CAD tool, so they just worked in a familiar CAD. This use of various $\mathrm{CAD}$ tools resulted in $\mathrm{CAD}$ models without feature tree and consequently longer iteration cycles. On the other hand, most of the students reported that in the workshop, they already knew the benefit of collaborative whiteboards such as Miro, so they used it extensively during the course.

\subsection{File sharing and potential of cloud-based ICT tools}

Most of the taskwork within the analysed teams is conducted individually. Team members conduct various searches, sketch their ideas, and model in CAD individually. Teams must integrate that individual work into the whole. Hence, no matter which ICT tools team members use to conduct their work, they have to share their insights with other members. While common platforms such as cloudrepositories are used across all teams, there is a huge potential in cloud-based alternatives of the 
commonly used ICT tools. These tools enable team members to work individually and skip the task of file sharing and help them to easier integrate their work into that of the whole team. Furthermore, these cloud-based ICT tools enable synchronous work, which is crucial as some of the most important product design tasks, such as generating ideas, are usually conducted as team activities. Therefore, cloud-based ICT tools should be beneficial to product design teams as these platforms enable doing taskwork and share knowledge in both synchronous and asynchronous manner.

Some of these tools were introduced to students, with usually positive feedback from the adopters. One example is a collaborative whiteboard (Miro) which students use extensively during the opportunity identification and conceptual design phases (Verstegen et al., 2016; Vukašinović and Pavković, 2017). Students used this tool for individual and both asynchronous and synchronous types of team working. Another is a task management tool (Trello), which helped students staying on track as they always had available the current state of their project and tasks that the team is currently working on. The introduction of cloud-based CAD tools in two teams received slightly lower adoption. Team members that adopted these tools reported that they are useful for this type of project due to their up-to-date representation, easier exchange of information between team members, and easier distribution of work. Few teams also used cloud-based document writing tools (e.g. Google Docs) whenever input from all the team members was expected, such as writing report. These teams usually showed the same transition while making a presentation (using, e.g. Google Presentation). Looking at Figure 1, only tasks that were not covered by cloud-based ICT tools include those related to technology, idea and market search. The introduction of cloud-based collaborative tools related to team-based internet searches might be beneficial to students.

Therefore, introducing new ICT tools might be beneficial for teams. Still, this introduction has to be organised considering students' previous knowledge and experience (Brisco et al., 2016, 2019) to avoid overloading students with new information (Verstegen et al., 2016).

\subsection{Implications}

This paper provides various implications for research, education and practice. Given the importance of previous experience and problems with adopting new ICT tools in PD teams, researchers who analyse the use of ICT tools should ensure that the team under analysis has a proper understanding of its functionalities and tasks to use the tools. Furthermore, the lack of cloud-based collaborative ICT tools for information retrieval (e.g. patent and internet searches) implies that technology development researchers might consider exploring the advantages of these solutions.

Educators could use these findings as a guideline to organise their project-based courses. The proposed approach is to identify best practices on the use of specific ICT tools for the course context and to identify students' current experience with using these tools. While giving initial instructions on tool usage, educators should be considerate and not overload students with information.

When learning new ICT tools, teams (including student teams) should understand the tools' potential benefits as it might help them during the initial period of the tool adoption. Furthermore, the teams should focus on using cloud-based tools so that their work could be easily shared and reflect one of the real-world. These cloud-based tools might be beneficial for teams working remotely or are being forced to work so, due to lockdowns caused by pandemic such as COVID-19.

\section{CONCLUSIONS}

The paper presents results on the use of ICT tools during the distributed product design PBL course. The results show that teams utilise various ICT tools to help them work on a design problem. Some tools are used for only one purpose, while others are used for various tasks. Furthermore, students often use more than one ICT tool for the same task. As students utilise tools based on previous experience, the course staff designed an initial workshop focused on active learning of the product design process and supporting tools. Students utilised proposed ICT tools and used them extensively during the course. The exception was CAD-related use, which was introduced to teams later throughout the course and was based on self-learning. Additionally, students often utilised cloud-based tools that help them to work synchronously on the same document. Hence, cloud-based collaborative tools have great potential for PBL courses, but the course staff should carefully introduce them to students. 
These results provide educators with specific ICT tools that they might incorporate into product design PBL courses and with the approach on how to introduce those tools. Furthermore, distributed teams should take time and learn about using cloud-based ICT tools that enable synchronous work.

Future work should focus on a more thorough assessment of the ICT tool use (e.g., describe their use over time) and generalise our findings for product design teams.

\section{ACKNOWLEDGMENTS}

This paper reports on work funded by the Erasmus+ project 2018-1-HR01-KA203-047486: ELPID E-learning Platform for Innovative Product Development (http://www.elpid.org/) and the Croatian Science Foundation project IP-2018-01-7269: Team Adaptability for Innovation-Oriented Product Development - TAIDE (http://www.taide.org). The authors would like to thank the ELPID coaches and students for their assistance in data collection.

\section{REFERENCES}

Becattini, N., Cascini, G. and Rotini, F. (2015), "OTSM-TRIZ Network of Problems for evaluating the design skills of engineering students", Procedia Engineering, available at: https://doi.org/10.1016/j.proeng.2015.12.356.

Becattini, N., Škec, S., Pavković, N. and Cascini, G. (2020), "E-Learning Infrastructure Prototype for Geographically Distributed Project-Based Learning", Proceedings of the Design Society: DESIGN Conference, available at: https://doi.org/10.1017/dsd.2020.282.

Brisco, R., Whitfield, R.I. and Grierson, H. (2016), "Recommendations for the use of social network sites and mobile devices in a collaborative engineering design project", Proceedings of the 18th International Conference on Engineering and Product Design Education: Design Education: Collaboration and CrossDisciplinarity, E and PDE 2016.

Brisco, R., Whitfield, R.I. and Grierson, H. (2020), “A novel systematic method to evaluate computer-supported collaborative design technologies", Research in Engineering Design, available at: https://doi.org/10.1007/s00163-019-00323-7.

Brisco, R., Whitfield, R.I., Grierson, H. and Bohemia, E. (2019), "Overcoming the challenges of global collaboration through design education”, DS 95: Proceedings of the 21st International Conference on Engineering and Product Design Education (E\&PDE 2019), University of Strathclyde, Glasgow. 12th -13th September 2019, The Design Society, available at: https://doi.org/10.35199/epde2019.73.

Cash, P., Škec, S. and Štorga, M. (2019), "The dynamics of design: exploring heterogeneity in meso-scale team processes", Design Studies, available at: https://doi.org/10.1016/j.destud.2019.08.001.

Dym, C.L., Agogino, A.M., Eris, O., Frey, D.D. and Leifer, L.J. (2005), "Engineering design thinking, teaching, and learning", Journal of Engineering Education, available at: https://doi.org/10.1002/j.21689830.2005.tb00832.x.

Hmelo-Silver, C.E. (2004), “Problem-based learning: What and how do students learn?", Educational Psychology Review, available at: https://doi.org/10.1023/B:EDPR.0000034022.16470.f3.

Kawakami, T., Barczak, G. and Durmuşoğlu, S.S. (2015), "Information Technology Tools in New Product Development: The Impact of Complementary Resources*, $\uparrow "$, Journal of Product Innovation Management, Vol. 32 No. 4, pp. 622-635.

Leung, W., Wang, Y. and Kim, S.W. (2019), "Global product development: Project-based multidisciplinary joint course", Proceedings of the 21st International Conference on Engineering and Product Design Education: Towards a New Innovation Landscape, E and PDE 2019, available at: https://doi.org/10.35199/epde2019.55.

Pahl, G., Beitz, W., Feldhusen, J. and Grote, K.H. (2007), Engineering Design; A Systematic Approach, Third Edit., Springer-Verlag London Limited, London.

Robson, C. and McCartan, K. (2016), Real World Research, Wiley.

Stone, W.L., Pierce, R.S. and Kaul, S. (2018), "Promoting innovation in a junior-level, multidisciplinary, electro-mechanical design course", ASEE Annual Conference and Exposition, Conference Proceedings, available at: https://doi.org/10.18260/1-2--30907.

Verstegen, D.M.L., de Jong, N., van Berlo, J., Camp, A., Könings, K.D., van Merriënboer, J.J.G. and Donkers, J. (2016), "How e-Learning Can Support PBL Groups: A Literature Review", available at: https://doi.org/10.1007/978-3-319-08275-2_2.

Vukašinović, N. and Pavković, N. (2017), "Use of virtual mobility to facilitate modern project-based NPD education", International Journal of Engineering Education.

Xiao, A., Zhang, A.S. and Tam, J. (2018), "Product development process and student learning in an engineering technology capstone project: Electrical Go-Kart", ASEE Annual Conference and Exposition, Conference Proceedings, available at: https://doi.org/10.18260/1-2--30894. 